\title{
EMISSÃO DE CO 2 DO SOLO ASSOCIADA À CALAGEM EM ÁREA DE CONVERSÃo DE LARANJA PARA CANA-DE-AÇÚCAR
}

\author{
ELITON DE F. SILVA ${ }^{1}$, MARA R. MOITINHO ${ }^{2}$, DANIEL DE B. TEIXEIRA ${ }^{3,}$ \\ GENER T. PEREIRA ${ }^{4}$, NEWTON LA SCALA JUNIOR ${ }^{5}$
}

\begin{abstract}
RESUMO: A emissão de $\mathrm{CO}_{2}$ do solo $\left(\mathrm{FCO}_{2}\right)$ em áreas agrícolas é resultante da interação de diversos fatores, sendo alterada pela prática de manejos do solo e da cultura, além das condições edafoclimáticas locais. Neste estudo, objetivou-se quantificar a $\mathrm{FCO}_{2}$ em função da calagem e posição da aplicação (antiga linha e entrelinha) da cultura da laranja em área de conversão para a cultura da cana-de-açúcar, no município de Frutal-MG. Os tratamentos avaliados foram: Linha/CC (linha com aplicação de calcário); Entrelinha/CC (entrelinha com aplicação de calcário); Linha/SC (linha sem aplicação de calcário), e Entrelinha/SC (entrelinha sem aplicação de calcário). $\mathrm{FCO}_{2}$, temperatura do solo (Ts) e umidade do solo (Us) foram avaliadas durante 12 dias. O maior valor médio da $\mathrm{FCO}_{2}$ ao longo do período de estudo foi observado no tratamento Linha/CC $(9,63 \mu \mathrm{mol}$ $\left.\mathrm{m}^{-2} \mathrm{~s}^{-1}\right)$; e o menor, no tratamento Entrelinha/CC $\left(5,92 \mu \mathrm{mol} \mathrm{m} \mathrm{m}^{-2} \mathrm{~s}^{-1}\right)$, segundo teste de Tukey. A $\mathrm{FCO}_{2}$ foi negativamente correlacionada à Us na Linha/CC $(\mathrm{r}=-0,56 ; p<0,05)$ e na Linha/SC $(\mathrm{r}=-$ $0,66 ; p<0,05)$. Entre a $\mathrm{FCO}_{2}$ e a Ts, verificou-se correlação positiva e significativa na Linha/CC (r $=0,76 ; p<0,001)$, na Linha/SC $(\mathrm{r}=0,89 ; p<0,001)$ e na Entrelinha/SC $(\mathrm{r}=0,66 ; p<0,05)$. Observou-se que a calagem e a posição de aplicação (linha e entrelinha) influenciaram nas emissões de $\mathrm{CO}_{2}$ do solo.
\end{abstract}

PALAVRAS-CHAVE: calagem, respiração do solo, temperatura do solo, umidade do solo.

\section{SOIL $\mathrm{CO}_{2}$ EMISSION ASSOCIATED WITH LIMING IN AREA OF CONVERSION OF ORANGE FOR SUGAR CANE}

\begin{abstract}
The soil $\mathrm{CO}_{2}$ emission $\left(\mathrm{FCO}_{2}\right)$ in agricultural areas is resulting from the interaction of several factors, as amended by the practice of soil management practices and crop, in addition to the local edaphoclimatic conditions. In this study, we aimed to quantify $\mathrm{FCO}_{2}$ influenced by liming and application position (row and interrow old) of the orange crop in conversion area for cultivation of sugar cane in the municipality of Frutal-MG. The treatments evaluated were: Row/CC (row with lime application), Interrow/CC (interrow with application of lime), Row/SC (row without liming) and Interrow/SC (interrow without liming). $\mathrm{FCO}_{2}$, temperature (Ts) and soil moisture (Us) were evaluated over 12 days. The highest average value of $\mathrm{FCO}_{2}$ over the study period was observed in the treatment Row/CC $\left(9.63 \mu \mathrm{mol} \mathrm{m} \mathrm{m}^{-2} \mathrm{~s}^{-1}\right)$ and the lowest in Interrow/CC $\left(5.92 \mu \mathrm{mol} \mathrm{m}^{-2} \mathrm{~s}^{-1}\right)$ according to the Tukey test. The $\mathrm{FCO}_{2}$ was negatively correlated with Us in Row/CC $(\mathrm{r}=-0.56, p$ $<0.05)$ and in Row/SC ( $\mathrm{r}=-0.66, p<0.05)$. It was also observed a significant and positive correlation between $\mathrm{FCO}_{2}$ and Ts in Row/CC ( $\left.\mathrm{r}=0.76, p<0.001\right)$, Row/SC $(\mathrm{r}=0.89, p<0.001)$ and in Interrow/SC $(\mathrm{r}=0.66, p<0.05)$. It was observed that liming and position of application (row and interrow) influenced the soil $\mathrm{CO}_{2}$ emissions.
\end{abstract}

KEYWORDS: liming, soil respiration, soil temperature, soil moisture.

\footnotetext{
${ }^{1}$ Físico, Mestre em Agronomia (Ciência do Solo), Departamento de Ciências Exatas, UNESP/Jaboticabal - SP, Fone: (16) 32092624, elitonfrutal@bol.com

${ }^{2}$ Bióloga, Doutoranda em Agronomia (Ciência do Solo), Departamento de Ciências Exatas, UNESP/Jaboticabal SP,maramoitinho@gmail.com

${ }^{3}$ Engenheiro Agrônomo, Doutorando em Agronomia (Produção Vegetal), Departamento de Solos e Adubos, UNESP/Jaboticabal SP, daniel.dbt@ hotmail.com

${ }^{4}$ Estatístico, Professor Adjunto, Departamento de Ciências Exatas, UNESP/Jaboticabal - SP, genertp@ @cav.unesp.br

${ }^{5}$ Físico, Professor Adjunto, Departamento de Ciências Exatas, UNESP/Jaboticabal - SP, lascala@ @cav.unesp.br

Recebido pelo Conselho Editorial em: 10-12-2013

Aprovado pelo Conselho Editorial em: 7-4-2014
} 


\section{INTRODUÇÃO}

A concentração de dióxido de carbono $\left(\mathrm{CO}_{2}\right)$ e de outros gases de efeito estufa, como o metano $\left(\mathrm{CH}_{4}\right)$ e o óxido nitroso $\left(\mathrm{N}_{2} \mathrm{O}\right)$ na atmosfera, tem aumentado consideravelmente, atingindo taxas crescentes de $\mathrm{CO}_{2}$ da ordem de 80\% entre 1970 e 2004 (IPCC, 2007); embora o potencial de aquecimento global do $\mathrm{CH}_{4}$ e do $\mathrm{N}_{2} \mathrm{O}$ seja, respectivamente, 25 e 298 vezes maior que o do $\mathrm{CO}_{2}$, o dióxido de carbono apresenta a maior contribuição em termos relativos para o efeito estufa adicional devido à sua grande quantidade emitida (IPCC, 2007).

$\mathrm{O}$ processo de emissão de $\mathrm{CO}_{2}$ do solo está associado à atividade microbiana, respiração das raízes, decomposição dos resíduos vegetais, oxidação da matéria orgânica do solo (MOS) (LAL, 2009) e aplicação de calcário para a correção do pH do solo (FUENTES et al., 2006; ALMARAZ et al., 2009). Segundo o fator de emissão adotado pelo IPCC (2006), a emissão provocada pela calagem realizada com calcário dolomítico é de $0,13 \mathrm{t} \mathrm{C}-\mathrm{CO}_{2}$ por tonelada de calcário aplicado no solo, que representa o conteúdo equivalente de carbonato material $\left(13 \%\right.$ para $\left.\mathrm{CaMg}\left(\mathrm{CO}_{3}\right)_{2}\right)$, supondo-se que todo o carbono do calcário aplicado é emitido na forma de $\mathrm{CO}_{2}$ no ano da aplicação. Como consequência, ocorre um significativo aumento da atividade microbiana do solo medido pela quantidade adicional de $\mathrm{CO}_{2}$ emitido após a calagem (FUENTES et al., 2006).

As intensas atividades de preparo do solo durante operações de reforma de áreas agrícolas também aumentam, inicialmente, as taxas de emissão de $\mathrm{CO}_{2}$ do solo para a atmosfera, pois com o rompimento dos agregados do solo, parte do carbono anteriormente protegido em seu interior tornase mais suscetível à mineralização, devido a sua exposição à ação microbiana, favorecida pela maior oxigenação e pelas temperaturas mais elevadas do solo (LA SCALA et al., 2008; SCHWARTZ et al., 2010). Neste sentido, a atividade microbiana também é intensificada imediatamente após o preparo do solo. Entretanto, após um curto período, ocorre a redução das frações lábeis da matéria orgânica, e a atividade basal microbiana decresce (SIX et al., 2006).

A temperatura e a umidade do solo são as variáveis que melhor explicam as mudanças nas emissões de $\mathrm{CO}_{2}$ ao longo do tempo (COSTA et al., 2008; ALMARAZ et al., 2009; CHAVEZ et al., 2009; USSIRI \& LAL, 2009; ALMAGRO et al., 2009; PANOSSO et al., 2009; WANG et al., 2009; SILVA-OLAYA et al., 2013). A produção de $\mathrm{CO}_{2}$ pode ser favorecida ou inibida, dependendo do conteúdo de umidade do solo, sendo que há uma umidade ótima que maximiza a respiração (LINN \& DORAN, 1984). Em adição, a respiração microbiana do solo é limitada pela restrição da difusão de oxigênio necessário para a respiração aeróbia (LAL, 2009).

De acordo com dados da Companhia Nacional do Abastecimento (CONAB, 2013), as áreas destinadas à produção de cana-de-açúcar continuam em expansão pelo Brasil, sendo o Estado de São Paulo o maior produtor, com 51,87\%, seguido por Goiás, com 8,52\%, e Minas Gerais, com $8,47 \%$ do total da produção nacional. As áreas cultivadas com a cana-de-açúcar estão avançando sobre outros cultivos, como, por exemplo, o de laranja. Produtores desmotivados pelo preço baixo pago pela laranja, por problemas fitossanitários, pela queda no consumo mundial de suco de laranja, pela crise econômica internacional e pela estagnação das vendas internas, estão migrando para a cultura da cana-de-açúcar (CEPEA, 2013).

Por se tratar de um evento ainda recente, não há estudos que caracterizem o processo de emissão de $\mathrm{CO}_{2}$ nestas áreas de transição de culturas. Outro fator que pode ser destacado é o tipo de manejo adotado nas linhas e entrelinhas da cultura da laranja. O manejo é mais intensificado nas entrelinhas do que nas linhas, uma vez que as operações de pulverização, calagem e colheitas são feitas usando diretamente as entrelinhas. É interessante investigar estes dois locais separadamente, sob a hipótese de que tanto a calagem quanto a posição da aplicação da calagem estimulam maiores emissões de $\mathrm{CO}_{2}$ em áreas agrícolas com um histórico de diferentes manejos na linha e na entrelinha. Assim, objetivou-se quantificar a emissão de $\mathrm{CO}_{2}$ do solo em função da calagem e da posição de aplicação (antiga linha e entrelinha) da cultura da laranja em área de conversão desta, para a cultura da cana-de-açúcar, no município de Frutal-MG. 


\section{MATERIAL E MÉTODOS}

O estudo foi conduzido no município de Frutal-MG, no Triângulo Mineiro, com coordenadas geográficas, $19^{\circ} 91^{\prime}$ 59,98" de latitude sul e 48 95' 17,23" de longitude oeste, com $610 \mathrm{~m}$ acima do nível do mar. O solo foi classificado como Latossolo Vermelho-Amarelo distrófico típico (EMBRAPA, 2006). A área apresenta um relevo plano com declives de aproximadamente $3 \%$.

O clima da região foi classificado como Aw, de acordo com Köeppen, definido como tropical de verão chuvoso e inverno seco, com temperatura média anual de $22{ }^{\circ} \mathrm{C}$. A precipitação média anual é de $1.550 \mathrm{~mm}$, com período de maior concentração de outubro a março e com precipitações mais espaçadas, e de menores intensidades, de abril a setembro (Figura 1).

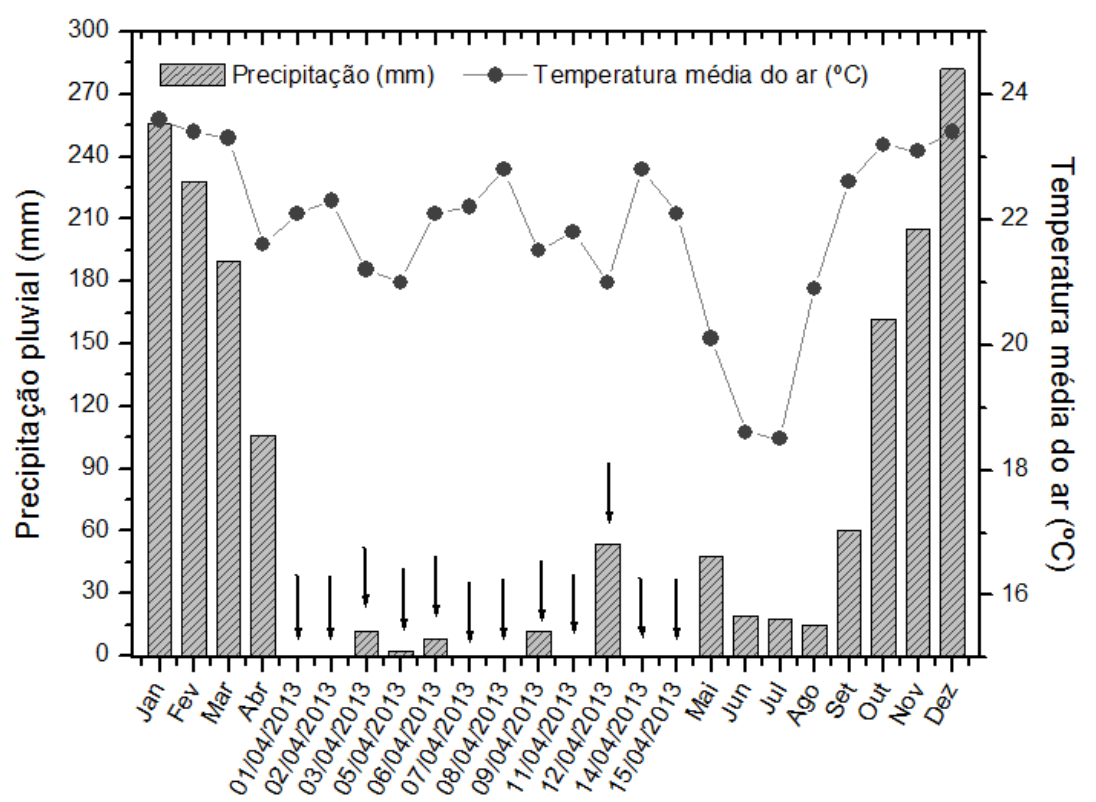

FIGURA 1. Dados das normais climatológicas em contraste aos dados das condições meteorológicas da época do experimento ( $1^{\circ}-04-2013$ a 15-04-2013). Flechas indicam os dias de avaliação da emissão de $\mathrm{CO}_{2}$, temperatura e umidade do solo. Data of climatological normals in contrast to data the meteorological conditions at the time of the experiment (01-04-2013 to 15-04-2013). Arrow indicate days of evaluation of $\mathrm{CO}_{2}$ emission, temperature and soil moisture.

A área experimental passa por uma transição de culturas agrícolas, vindo de um período de oito anos de ocupação com a cultura da laranja e atualmente se encontra com o primeiro plantio de cana-de-açúcar. Após a retirada dos pés de laranja, iniciou-se o processo de transição de culturas com as atividades de preparo do solo. Porém, antes de serem adotados os procedimentos de preparo, foram demarcados os limites referentes à linha e à entrelinha de plantio da laranja para posterior implantação dos colares de PVC e medições da emissão de $\mathrm{CO}_{2}$ do solo (Figura 2).

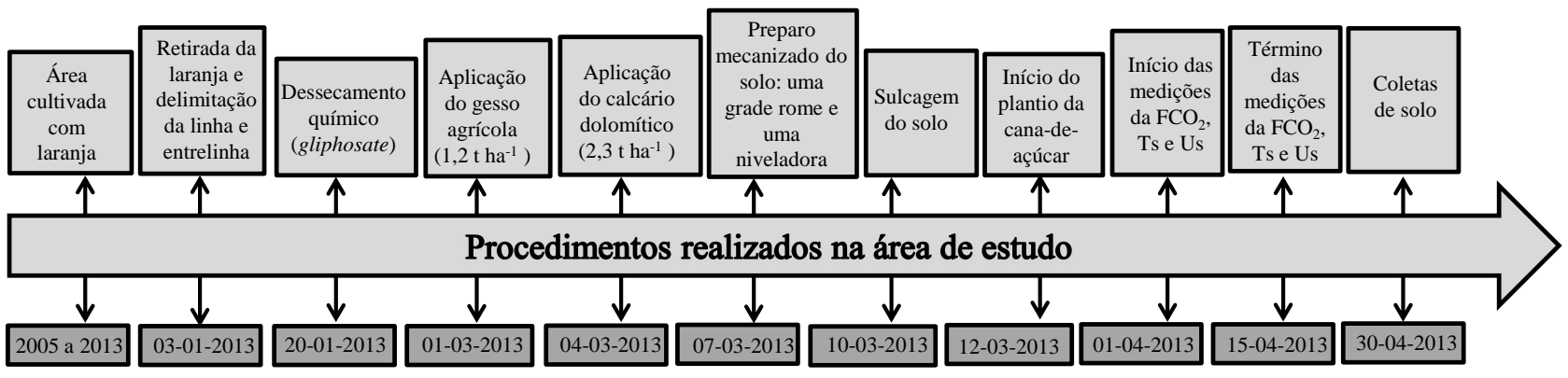

FIGURA 2. Ordem cronológica dos procedimentos realizados na área de estudo. Chronological order of procedures performed in the study area. 
Decorridos 20 dias do início do plantio da nova cultura (cana-de-açúcar), foram marcados 52 pontos e inseridos colares de PVC ao longo da área experimental, de $45 \times 75 \mathrm{~m}$, com espaçamento de $2 \mathrm{~m}$ entre os colares, para as avaliações da emissão de $\mathrm{CO}_{2}\left(\mathrm{FCO}_{2}\right)$, temperatura do solo (Ts) e umidade do solo (Us), sendo 13 pontos em cada tratamento: Linha/CC (antiga linha da laranja com aplicação de calcário); Entrelinha/CC (antiga entrelinha da laranja com aplicação de calcário); Linha/SC (antiga linha da laranja sem aplicação de calcário), e Entrelinha/SC (antiga entrelinha da laranja sem aplicação de calcário) (Figura 3). Foram 12 dias de avaliações compreendidos num período de 15 dias $(01 ; 02 ; 03 ; 05 ; 06 ; 07 ; 08 ; 09 ; 11 ; 12 ; 14$ e 15 de abril de 2013), no horário matutino, das 8 às 10h30 (Figura 1). Utilizando-se da denominação do dia Juliano, essas datas correspondem a 91; 92; 93; 95; 96; 97; 98; 99; 101; 102; 104 e 105 de 2013.

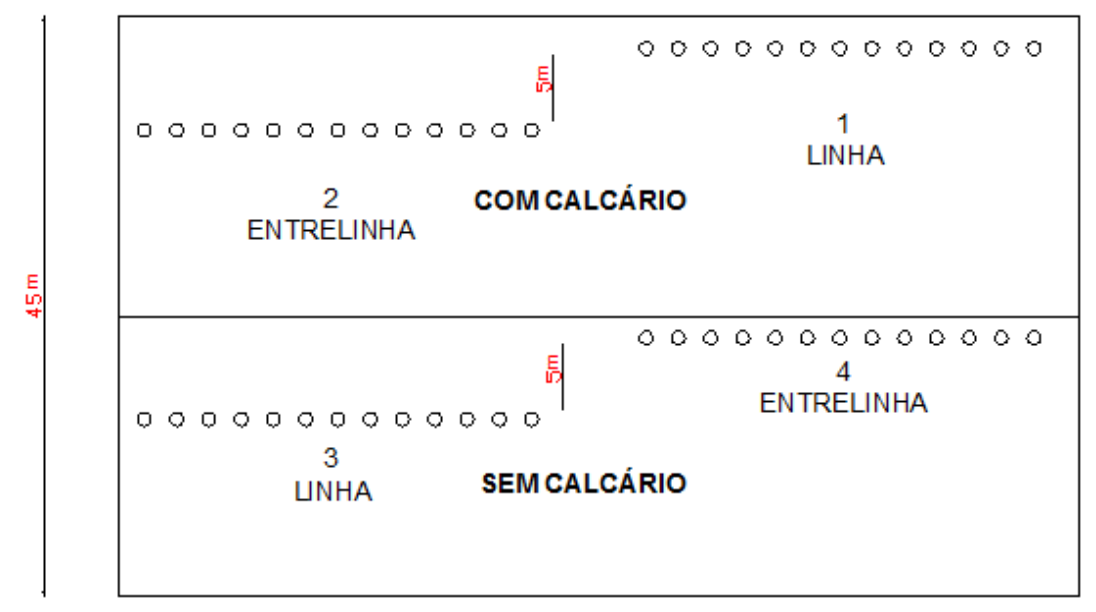

FIGURA 3. Descrição de montagem do experimento. $o=$ colares de PVC onde foram realizadas as medições; 1 e 2 = áreas com aplicação de calcário; 3 e 4 = áreas sem aplicação de calcário; LINHA = antiga linha da laranja; ENTRELINHA = antiga entrelinha da laranja. Description mounting experiment. $0=$ necklaces PVC where measurements were performed; 1 and $2=$ areas with lime application; 3 and $4=$ areas without liming; LINHA = old orange row; ENTRELINHA = old orange interrow.

A $\mathrm{FCO}_{2}$ foi registrada utilizando-se de um sistema portátil da companhia LI-COR (LI-8100), Nebraska EUA. Em seu modo de medição, o sistema monitora as mudanças na concentração de $\mathrm{CO}_{2}$ dentro da câmera, por meio de espectroscopia de absorção óptica na região do infravermelho (IRGA). A câmera para solos tem um volume interno de $854,2 \mathrm{~cm}^{3}$, com área de contato de $83,7 \mathrm{~cm}^{2}$, e foi colocada sobre colares de PCV previamente inseridos no solo, a uma profundidade de $3 \mathrm{~cm}$ em cada um dos pontos amostrais. Uma vez a câmara fechada, o modo de medida levou 1 min $30 \mathrm{~s}$, em cada ponto, para a determinação de $\mathrm{FCO}_{2}$, em que a concentração de $\mathrm{CO}_{2}$ dentro da câmara foi determinada a cada 2 s 30 .

A Ts foi monitorada por um sensor de temperatura (termistor portátil), parte integrante do sistema do LI-8100, inserido na camada de 0-12 cm de profundidade. A Us também foi medida em todos os pontos, utilizando-se de um sistema portátil TDR-Campbel® (Hydrosense TM, Campbell Scientific, Australia), que avaliou a umidade disponível do solo (\% volume) na camada de 0-12 cm.

Ao final das medições, foram realizadas coletas de solo na camada de $0-20 \mathrm{~cm}$ de profundidade, sendo coletadas aleatoriamente 15 amostras simples em cada tratamento que, posteriormente, foram homogeneizadas, obtendo-se uma amostra composta para cada tratamento para fins de caracterização química do solo dos diferentes tratamentos avaliados (Tabela 1). 
TABELA 1. Propriedades químicas do solo nos diferentes tratamentos avaliados. Soil chemical properties in different evaluated treatments

\begin{tabular}{lcccc}
\hline \multirow{2}{*}{ Propriedades } & \multicolumn{4}{c}{ Tratamentos } \\
\cline { 2 - 5 } & Linha/CC & Entrelinha/CC & Linha/SC & Entrelinha/SC \\
\hline $\mathrm{pH}\left(\mathrm{H}_{2} \mathrm{O}\right)$ & 6,17 & 5,97 & 5,75 & 5,42 \\
$\mathrm{H}+\mathrm{Al}(\mathrm{mmolc} \mathrm{dm}$ & -3 & 14,45 & 21,11 & 18,41 \\
$\mathrm{Mg}\left(\mathrm{mmolc} \mathrm{dm}^{-3}\right)$ & 13,14 & 13,00 & 8,00 & 9,00 \\
$\mathrm{Ca}\left(\mathrm{mmolc} \mathrm{dm}^{-3}\right)$ & 15,00 & 41,00 & 34,00 & 35,00 \\
$\mathrm{~K}\left(\mathrm{mmolc} \mathrm{dm}^{-3}\right)$ & 52,00 & 0,59 & 0,95 & 2,10 \\
$\mathrm{P}\left(\mathrm{mg} \mathrm{dm}^{-3}\right)$ & 2,03 & 11,00 & 67,00 & 52,00 \\
$\mathrm{SB}\left(\mathrm{mmolc} \mathrm{dm}^{-3}\right)$ & 12,00 & 54,59 & 42,95 & 46,10 \\
$\mathrm{CTC}\left(\mathrm{mmolc} \mathrm{dm}^{-3}\right)$ & 69,03 & 69,04 & 64,06 & 64,51 \\
$\mathrm{~V}(\%)$ & 82,17 & 79,07 & 67,05 & 71,47 \\
$\mathrm{MOS}\left(\mathrm{g} \mathrm{dm}^{-3}\right)$ & 84,01 & 22,00 & 22,00 & 18,00 \\
\hline
\end{tabular}

$\mathrm{Ca}=$ cálcio trocável; $\mathrm{Mg}=$ magnésio trocável $; \mathrm{H}+\mathrm{Al}=$ acidez potencial; $\mathrm{K}=$ potássio trocável; $\mathrm{P}=$ fósforo; $\mathrm{SB}=$ soma de bases; $\mathrm{CTC}$ = capacidade de troca catiônica; $\mathrm{V} \%$ = saturação por bases; $\mathrm{MOS}=$ matéria orgânica do solo. $\mathbf{C a}=\mathbf{e x c h a n g e a b l e ~ c a l c i u m ; ~} \mathbf{M g}=$ exchangeable magnesium; $\mathrm{H}+\mathrm{Al}=$ potential acidity; $\mathrm{K}=$ exchangeable potassium; $\mathrm{P}=$ phosphorus; $\mathrm{SB}=$ sum of bases; $\mathrm{CEC}$ = cation exchange capacity; $\mathrm{V} \%$ = base saturation; $\mathrm{SOM}=$ soil organic matter.

Os dados foram analisados, inicialmente, por meio da estatística descritiva (média, erro-padrão da média, desvio-padrão, máximo, mínimo e coeficiente de variação). A análise de variância foi realizada em delineamento inteiramente casualizado, no esquema de medidas repetidas no tempo. A comparação de médias foi realizada por meio do teste de Tukey, ao nível de significância de $5 \%$ de probabilidade. As análises de variância e de correlação linear entre as variáveis foram realizadas, utilizando o sistema SAS (SAS versão 9.1, SAS instituto, Cary, NC, EUA). As emissões acumuladas de $\mathrm{CO}_{2}$ do solo, durante todo o período de estudo, foram estimadas pelo método da área abaixo das curvas de emissão, utilizando o software $\mathrm{R}$ ( $\mathrm{R}$ Development Core Team, 2011).

\section{RESULTADOS E DISCUSSÃO}

\section{Efeito da calagem}

Os maiores valores médios da $\mathrm{FCO}_{2}$, ao longo do período de estudo, foram observados no tratamento Linha/CC $\left(9,63 \mu \mathrm{mol} \mathrm{m} \mathrm{m}^{-2} \mathrm{~s}^{-1}\right)$, onde também foi constatado, após análise química, maior

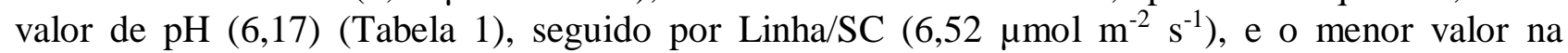
Entrelinha/SC $\left(4,63 \mu \mathrm{mol} \mathrm{m} \mathrm{m}^{-1}\right)$, ambos diferindo significativamente $(p<0,05)$. Somente os tratamentos Entrelinha/CC e Linha/SC não diferiram $(p>0,05)$ (Tabela 2).

O efeito da calagem na linha pode ser observado quando se comparam Linha/CC e Linha/SC, sendo a $\mathrm{FCO}_{2} 48 \%$ superior quando realizada a calagem. Em relação à Entrelinha/CC e Entrelinha/SC, a $\mathrm{FCO}_{2}$ foi $41 \%$ maior, também, no tratamento com aplicação de calcário.

Situação semelhante foi constatada por MARCELO et al. (2012), em estudo para avaliar o efeito da calagem na respiração do solo, no qual se verificou que, quando o calcário foi aplicado na dose recomendada, a emissão de $\mathrm{CO}_{2}$ foi $24 \%$ maior quando comparada à do solo sem aplicação de calcário.

A calagem é uma importante fonte de emissão de $\mathrm{CO}_{2}$ do solo, sendo o calcário calcítico $\left(\mathrm{CaCO}_{3}\right)$ ou dolomítico $\mathrm{CaMg}\left(\mathrm{CO}_{3}\right)_{2}$, o carbonato dissolve-se e libera bicarbonato $\left(2 \mathrm{HCO}_{3}\right)$, que evolui em $\mathrm{CO}_{2}$ e água $\left(\mathrm{H}_{2} \mathrm{O}\right)$ (IPCC, 2006). Embora maiores emissões de $\mathrm{CO}_{2}$ sejam resultantes de reações de hidrólise do carbonato de cálcio no solo, a atividade microbiana também se intensifica após o processo de calagem pela melhoria das condições químicas do solo (FUENTES et al., 2006). 
TABELA 2. Estatísticas descritivas da emissão de $\mathrm{CO}_{2}$, temperatura e umidade do solo nos tratamentos: Linha/CC, Entrelinha/CC, Linha/SC e Entrelinha/SC. Descriptive statistics of the emission of $\mathrm{CO}_{2}$, temperature and soil moisture treatments: Row/CC, Interrow/CC, Row/SC and Interrow/SC.

\begin{tabular}{lcccccc}
\hline Tratamento & Média & EP & DP & Mínimo & Máximo & CV (\%) \\
\hline \multicolumn{7}{c}{ Emissão de $\mathrm{CO}_{2}$ do solo $\left(\mu \mathrm{mol} \mathrm{m}^{-2} \mathrm{~s}^{-1}\right)$} \\
\hline Linha/CC & $9,63 \mathrm{a}$ & 0,30 & 3,74 & 2,34 & 26,76 & 38,86 \\
Entrelinha/CC & $5,92 \mathrm{~b}$ & 0,19 & 2,40 & 1,11 & 15,88 & 40,51 \\
Linha/SC & $6,52 \mathrm{~b}$ & 0,25 & 3,14 & 1,21 & 15,35 & 48,22 \\
Entrelinha/SC & $4,63 \mathrm{c}$ & 0,26 & 3,30 & 0,42 & 33,19 & 71,38 \\
\hline \multicolumn{7}{c}{ Temperatura do solo $\left({ }^{\circ} \mathrm{C}\right)$} \\
\hline Linha/CC & $26,8 \mathrm{~b}$ & 0,14 & 1,69 & 22,39 & 29,76 & 6,29 \\
Entrelinha/CC & $26,7 \mathrm{~b}$ & 0,18 & 2,28 & 22,47 & 42,12 & 8,55 \\
Linha/SC & $27,6 \mathrm{a}$ & 0,17 & 2,07 & 22,39 & 31,16 & 7,50 \\
Entrelinha/SC & $27,5 \mathrm{a}$ & 0,17 & 2,13 & 22,37 & 31,86 & 7,74 \\
\hline \multicolumn{7}{c}{ Umidade do solo $(\%$ volume $)$} \\
Linha/CC & $12,01 \mathrm{~b}$ & 0,17 & 2,18 & 7,00 & 19,00 & 18,11 \\
Entrelinha/CC & $12,21 \mathrm{~b}$ & 0,18 & 2,22 & 8,00 & 19,00 & 18,21 \\
Linha/SC & $13,35 \mathrm{a}$ & 0,24 & 3,02 & 8,00 & 22,00 & 22,64 \\
Entrelinha/SC & $13,19 \mathrm{a}$ & 0,23 & 2,87 & 8,00 & 21,00 & 21,76 \\
\hline
\end{tabular}

$\mathrm{N}=156 ; \mathrm{DP}=$ desvio-padrão; $\mathrm{EP}$ = erro-padrão da média; $\mathrm{CV}$ = coeficiente de variação. Valores médios com a mesma letra não diferem entre si, pelo teste de Tukey, ao nível de $5 \%$ de probabilidade. $\mathbf{N}=\mathbf{1 5 6}, \mathbf{S D}=$ standard deviation, $\mathbf{S E}=\mathbf{s t a n d a r d}$ error of the mean, $\mathrm{CV}=$ coefficient of variation. Mean values with the same letter do not differ by Tukey test at $5 \%$ probability.

Em adição, os maiores valores médios da temperatura do solo (Ts), no decorrer do período estudado, foram observados nos tratamentos onde não houve a aplicação de calcário, Linha/SC $\left(27,6{ }^{\circ} \mathrm{C}\right)$ seguido pela Entrelinha/SC $\left(27,5^{\circ} \mathrm{C}\right)$. Assim como o ocorrido com a Ts, os maiores valores médios da umidade do solo (Us), durante o período, foram observados nos tratamentos sem aplicação de calcário: Linha/SC $(13,35 \%)$ e Entrelinha/SC $(13,19 \%)$, diferindo $(p<0,05)$ dos tratamentos: Linha/CC (12,01\%) e Entrelinha/CC (12,21\%) com os menores valores (Tabela 2).

\section{Efeito da posição da aplicação do calcário}

A posição de aplicação (linha e entrelinha) também influenciou a $\mathrm{FCO}_{2}$, sendo que as maiores emissões foram observadas na linha de plantio, independentemente da aplicação de calcário. Este efeito pode ser observado ao comparar os tratamentos: Linha/SC e Entrelinha/CC, onde o solo não corrigido pela calagem apresentou valores médios semelhantes ao solo com aplicação de calcário.

Assim, quando a aplicação da calagem foi realizada na antiga linha da laranja (Linha/CC), observa-se que este tratamento foi responsável por uma emissão $49 \%$ e $64 \%$ maior quando comparada àquela referente aos tratamentos Linha/SC e Entrelinha/CC, respectivamente. Estudos conduzidos em diferentes condições edafoclimáticas reportaram que a calagem foi a principal responsável pelo incremento na taxa de emissão de $\mathrm{CO}_{2}$ do solo para a atmosfera (FUENTES et al., 2006; ALMARAZ et al., 2009; MARCELO et al., 2012). Entretanto, poucos estudos fazem referência a diferentes posições de aplicação da calagem e possível efeito sobre a emissão de $\mathrm{CO}_{2}$ do solo, caracterizando em isolado a linha e a entrelinha de plantio de culturas.

Todavia, é importante salientar que estes dois locais são manejados de forma diferente, a exemplo da área do presente estudo, onde as operações de manejo eram mais intensificadas nas entrelinhas do que nas linhas da cultura da laranja. E que, embora as medições da $\mathrm{FCO}_{2}$ tenham sido realizadas na área de implantação da nova cultura da cana-de-açúcar, onde o preparo do solo tenha sido realizado com o intuito de deixar a área o mais homogênea possível, os resultados demonstram que existe uma delimitação de linha e entrelinha da antiga cultura da laranja, que influi sobre a $\mathrm{FCO}_{2}$. 
Diante dessa constatação e dos elevados valores observados para a $\mathrm{FCO}_{2}$ nos diferentes tratamentos avaliados, possivelmente, o preparo do solo composto por duas gradagens, realizado na área, também pode estar influenciando o fluxo de $\mathrm{CO}_{2}$ do solo para a atmosfera. Maiores emissões de $\mathrm{CO}_{2}$ induzidas pelo preparo do solo também têm sido reportadas por diversos autores (LA SCALA et al., 2008; TEIXEIRA et al., 2010; SILVA-OLAYA et al., 2013). Com a atividade de preparo, ocorre a exposição do carbono antes protegido no interior dos agregados do solo que, associado à maior oxigenação de solo e a temperaturas mais elevadas, favorece a atividade decompositora dos microrganismos, resultando em maiores emissões de $\mathrm{CO}_{2}$ do solo para a atmosfera a curto prazo. Contudo, pode existir um efeito combinado de curto e longo prazos (SCHWARTZ et al., 2010). O efeito de curto prazo do preparo seria o resultado de distúrbios físicos do solo, com o rompimento dos agregados. Já o efeito do preparo do solo a longo prazo sobre o fluxo de $\mathrm{CO}_{2}$ parece estar mais relacionado às alterações nas propriedades do solo (KESSAVALOU et al., 1998), principalmente em sua estrutura.

Para a Ts e a Us, a posição da aplicação do calcário não influenciou em seus valores, uma vez que, para ambas, não houve diferença significativa $(p>0,05)$ entre os tratamentos: Linha/CC e Entrelinha/CC, e entre os tratamentos: Linha/SC e Entrelinha/SC (Tabela 2).

\section{Variabilidade temporal da $\mathrm{FCO}_{2}$, Ts e Us}

$\mathrm{O}$ coeficiente de variação $(\mathrm{CV})$ observado para a $\mathrm{FCO}_{2}$ nos diferentes tratamentos avaliados é considerado alto $(\mathrm{CV}>24 \%)$, médio $(\mathrm{CV}<24 \%)$ para a Us, e baixo $(\mathrm{CV}<12 \%)$ para a Ts, segundo o critério de classificação proposto por WARRICK \& NIELSEN (1980). LA SCALA et al. (2003), avaliando a variabilidade espacial e temporal da emissão de $\mathrm{CO}_{2}$ em solo desprovido de vegetação, encontraram valores menores do CV (20,3\% a 28,7\%) para esta propriedade.

Os resultados da análise de variância de medidas repetidas no tempo para a $\mathrm{FCO}_{2}$, Ts e Us indicam um efeito significativo $(p<0,001)$ da interação entre a posição (linha e entrelinha), a aplicação (com aplicação ou sem a aplicação de calcário) e o tempo (dias de avaliação). Portanto, o padrão de variabilidade temporal da $\mathrm{FCO}_{2}$, Ts e Us não foi o mesmo para os tratamentos ao longo dos dias avaliados. Assim, faz-se necessário desdobrar os graus de liberdade desta interação tripla. As médias diárias da $\mathrm{FCO}_{2}$, Ts e Us estão apresentadas nas Tabelas 3, 4 e 5 e ilustradas na Figura $4 \mathrm{a}, \mathrm{b}$ e c, respectivamente.

$\mathrm{O}$ tratamento Linha/CC apresentou os maiores valores de $\mathrm{FCO}_{2}$ em todos os dias, quando comparado aos demais tratamentos avaliados. Os valores médios diários da $\mathrm{FCO}_{2}$ variaram de 12,23 $\mu \mathrm{mol} \mathrm{m} \mathrm{s}^{-1}$ (dia 102) a 4,63 $\mu \mathrm{mol} \mathrm{m}^{-2} \mathrm{~s}^{-1}$ (dia 104) (Tabela 3 e Figura 4a).

TABELA 3. Desdobramento da interação entre os níveis do fator posição de plantio x níveis do fator aplicação do calcário para cada dia avaliado para a emissão de $\mathrm{CO}_{2}$ do solo $\left(\mu \mathrm{mol} \mathrm{m} \mathrm{m}^{-2} \mathrm{~s}^{-1}\right)$.

Unfolding of the interaction between the levels of the factor planting position $\mathbf{x}$ factor level liming for each day for the emission of soil $\mathrm{CO}_{2}\left(\mu \mathrm{mol} \mathrm{m} \mathrm{m}^{-2} \mathrm{~s}^{-1}\right)$.

\begin{tabular}{|c|c|c|c|c|c|c|}
\hline \multirow{2}{*}{ Tratamento } & \multicolumn{6}{|c|}{ Dias Julianos } \\
\hline & 91 & 92 & 93 & 95 & 96 & 97 \\
\hline Linha/CC & $9,65 \mathrm{Aab}$ & $10,34 \mathrm{Aab}$ & 9,90 Aab & 10,39 Aab & $7,91 \mathrm{Ab}$ & $10,56 \mathrm{Aab}$ \\
\hline Entrelinha/CC & $5,58 \mathrm{BCabc}$ & $5,99 \mathrm{Bab}$ & $5,89 \mathrm{Bab}$ & $6,29 \mathrm{Cab}$ & $4,82 \mathrm{Bbc}$ & 7,46 Bab \\
\hline Linha/SC & 7,17 $\mathrm{ABa}$ & $7,24 \mathrm{Ba}$ & $6,93 \mathrm{Ba}$ & $6,98 \mathrm{Ba}$ & $5,20 \mathrm{ABab}$ & $7,33 \mathrm{Ba}$ \\
\hline Entrelinha/SC & $3,81 \mathrm{Cbc}$ & 7,60 ABa & $6,09 \mathrm{Bab}$ & $5,67 \mathrm{Cab}$ & $3,73 \mathrm{Bbc}$ & 4,75 Babc \\
\hline \multirow{2}{*}{ Tratamento } & \multicolumn{6}{|c|}{ Dias Julianos } \\
\hline & 98 & 99 & 101 & 102 & 104 & 105 \\
\hline Linha/CC & $10,63 \mathrm{Aab}$ & 10,09 Aab & $8,77 \mathrm{Ab}$ & $12,23 \mathrm{Aa}$ & $4,63 \mathrm{Ac}$ & $10,45 \mathrm{Aab}$ \\
\hline Entrelinha/CC & $6,11 \mathrm{Bab}$ & 5,50 Babc & $6,25 \mathrm{ABab}$ & 6,33 BCab & $2,87 \mathrm{ABc}$ & 7,99 ABa \\
\hline Linha/SC & 7,59 Ba & $6,77 \mathrm{Ba}$ & $5,45 \mathrm{Bab}$ & $7,15 \mathrm{Ba}$ & $3,19 \mathrm{ABb}$ & $7,21 \mathrm{BCa}$ \\
\hline Entrelinha/SC & 4,85 Babc & $4,25 \mathrm{Bbc}$ & $4,05 \mathrm{Bbc}$ & $4,07 \mathrm{Cbc}$ & $2,20 \mathrm{Bc}$ & $4,50 \mathrm{CBC}$ \\
\hline
\end{tabular}

Médias seguidas pela mesma letra, minúsculas nas linhas e maiúsculas nas colunas, não diferem entre si, pelo teste de Tukey, ao nível de 5\% de significância. Means followed by the same letter, lowercase letters in the line sand uppercase letters in columns do not differ by Tukey test at $5 \%$ significance level. 
$\mathrm{Na}$ Entrelinha/CC, houve a variação de $7,99 \mu \mathrm{mol} \mathrm{m} \mathrm{m}^{-2} \mathrm{~s}^{-1}$ (dia 105) a 2,87 $\mu \mathrm{mol} \mathrm{m} \mathrm{m}^{-1}$ (dia 104). Na Linha/SC, esses valores corresponderam a $7,59 \mu \mathrm{mol} \mathrm{m}^{-2} \mathrm{~s}^{-1}$ (dia 98) e a $3,19 \mu \mathrm{mol} \mathrm{m}^{-2} \mathrm{~s}^{-}$ ${ }^{1}$ (dia 104), e na Entrelinha/SC os valores médios diários da $\mathrm{FCO}_{2}$ variaram de $7,6 \mu \mathrm{mol} \mathrm{m}^{-2} \mathrm{~s}^{-1}$ (dia 92) a $2,2 \mu \mathrm{mol} \mathrm{m}^{-2} \mathrm{~s}^{-1}$ (dia 104). No dia 104, houve as menores emissões de $\mathrm{CO}_{2}$ em todos os tratamentos avaliados (Tabela 3 e Figura $4 a$ ).
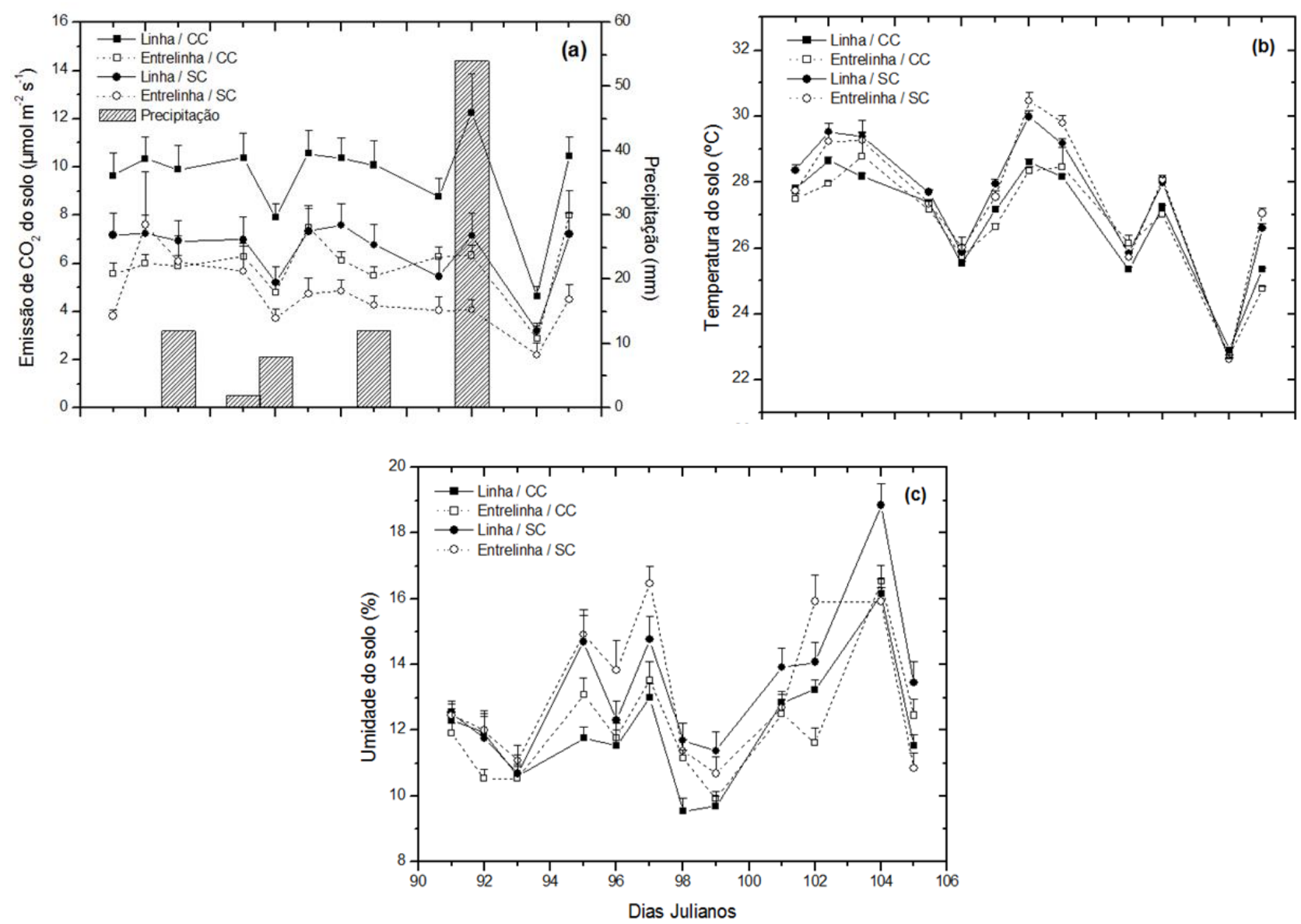

FIGURA 4. Emissão de $\mathrm{CO}_{2}$ do solo e precipitações ocorridas no período de estudo (a); temperatura (b), e umidade do solo (c), com metade da barra de erro-padrão nos tratamentos: Linha/CC, Entrelinha/CC, Linha/SC e Entrelinha/SC. $\mathbf{C O}_{2}$ emission from the soil and rainfall during the period of study (a), temperature (b) and soil moisture (c) with half the error bar standard treatments: Row/CC, Interrow/CC, Row/SC and Interrow/SC.

No tratamento Entrelinha/CC, a maior média da umidade do solo foi observada no dia 104 $(16,54 \%)$, e a menor, no dia $99(9,92 \%)$. Na Linha/CC, a maior média também foi registrada no dia $104(16,15 \%)$, e as menores, no dia 98 (9,54 \%), seguido do dia 99 (9,69\%). Na Entrelinha/SC, a maior média foi observada no dia 97 (16,46\%), e as menores, nos dias: 99 (10,69\%), 105 (10,85\%) e $93(11,08 \%)$. Na Linha/SC, a maior média da Us foi observada no dia $104(18,85 \%)$, e a menor, no dia $93(10,69 \%)$ (Tabela 4 e Figura 4c). 
TABELA 4. Desdobramento da interação entre os níveis do fator posição de plantio x níveis do fator aplicação do calcário para cada dia avaliado para a umidade do solo (\% volume).

Unfolding of the interaction between the levels of the factor planting position $x$ factor level liming for each day evaluated for soil moisture (\% volume).

\begin{tabular}{|c|c|c|c|c|c|c|}
\hline \multirow{2}{*}{ Tratamento } & \multicolumn{6}{|c|}{ Dias Julianos } \\
\hline & 91 & 92 & 93 & 95 & 96 & 97 \\
\hline Linha/CC & 9,65 Aab & 10,34 Aab & $9,90 \mathrm{Aab}$ & $0,39 \mathrm{Aab}$ & $7,91 \mathrm{~A} \mathrm{~b}$ & 10,56 Aab \\
\hline Entrelinha/CC & $5,58 \mathrm{BCabc}$ & $5,99 \mathrm{Bab}$ & 5,89 Bab & 6,29 Cab & $4,82 \mathrm{~B}$ bc & 7,46 Bab \\
\hline Linha/SC & 7,17 ABa & 7,24 Ba & $6,93 \mathrm{Ba}$ & $6,98 \mathrm{Ba}$ & 5,20 ABab & 7,33 $\mathrm{Ba}$ \\
\hline Entrelinha/SC & $3,81 \mathrm{Cbc}$ & $7,60 \mathrm{ABa}$ & 6,09 Bab & 5,67 Cab & 3,73 Bbc & 4,75 Babc \\
\hline \multirow{2}{*}{ Tratamento } & \multicolumn{6}{|c|}{ Dias Julianos } \\
\hline & 98 & 99 & 101 & 102 & 104 & 105 \\
\hline Linha/CC & $9,54 \mathrm{Bd}$ & $9,69 \mathrm{Bd}$ & $12,85 \mathrm{Abc}$ & $13,23 \mathrm{Bb}$ & $16,15 \mathrm{Ba}$ & $11,54 \mathrm{ABbcd}$ \\
\hline Entrelinha/CC & $11,15 \mathrm{ABbcd}$ & $\mathrm{d} \quad 9,92 \mathrm{ABd}$ & $13,38 \mathrm{Ab}$ & 11,62 Bbcd & $16,54 \mathrm{ABa}$ & $12,46 \mathrm{ABbC}$ \\
\hline Linha/SC & 11,69 Acde & 11,38 Ade & $13,92 \mathrm{Abc}$ & $14,08 \mathrm{ABbc}$ & $18,85 \mathrm{Aa}$ & 13,46 Abcd \\
\hline Entrelinha/SC & 11,38 ABde & $10,69 \mathrm{ABe}$ & 12,69 Acde & $15,92 \mathrm{Aab}$ & $15,92 \mathrm{Bab}$ & $10,85 \mathrm{Be}$ \\
\hline
\end{tabular}

$\mathrm{Na}$ Entrelinha/CC, a maior média da temperatura do solo foi constatada no dia $93\left(28,8{ }^{\circ} \mathrm{C}\right)$, seguido do dia $99\left(28,4^{\circ} \mathrm{C}\right)$, e a menor, no dia $104\left(22,7^{\circ} \mathrm{C}\right)$. $\mathrm{Na}$ Linha/CC, a maior média foi registrada no dia $92\left(28,6{ }^{\circ} \mathrm{C}\right)$, e a menor, no dia $104\left(22,9^{\circ} \mathrm{C}\right)$, e na Entrelinha/SC, os valores médios diários para a Ts variaram de $22,6{ }^{\circ} \mathrm{C}$ a $30,4{ }^{\circ} \mathrm{C}$ nos dias 104 e 98 , respectivamente (Tabela 5 e Figura 4b). No dia 104, assim como observado para a $\mathrm{FCO}_{2}$, foram registrados os menores valores médios da temperatura do solo para todos os tratamentos.

TABELA 5. Desdobramento da interação entre os níveis do fator posição de plantio x níveis do fator aplicação do calcário para cada dia avaliado para a temperatura do solo $\left({ }^{\circ} \mathrm{C}\right)$. Unfolding of the interaction between the levels of the factor planting position $x$ factor level liming for each day evaluated for soil temperature $\left({ }^{\circ} \mathrm{C}\right)$.

\begin{tabular}{|c|c|c|c|c|c|c|}
\hline \multirow{2}{*}{ Tratamento } & \multicolumn{6}{|c|}{ Dias Julianos } \\
\hline & 91 & 92 & 93 & 95 & 96 & 97 \\
\hline Linha/CC & $27,8 \mathrm{ABab}$ & $28,6 \mathrm{ABa}$ & $28,2 \mathrm{Bab}$ & $27,4 \mathrm{Ab}$ & $25,5 \mathrm{Ac}$ & $27,2 \mathrm{ABb}$ \\
\hline Entrelinha/CC & 27,5 Bbcd & $27,9 \mathrm{Babc}$ & $28,8 \mathrm{Bab}$ & 27,2 Acd & 25,7 Aef & 26,6 Bde \\
\hline Linha/SC & $28,3 \mathrm{Abc}$ & $29,6 \mathrm{Aa}$ & 29,3 Aab & 27,7 Acd & $25,9 \mathrm{Ae}$ & $27,9 \mathrm{Ac}$ \\
\hline Entrelinha/SC & $27,7 \mathrm{ABc}$ & $29,2 \mathrm{Ab}$ & $29,3 \mathrm{Ab}$ & $27,3 \mathrm{Ac}$ & 26,0 Ade & $27,6 \mathrm{ABc}$ \\
\hline \multirow{2}{*}{ Tratamento } & \multicolumn{6}{|c|}{ Dias Julianos } \\
\hline & 98 & 99 & 101 & 102 & 104 & 105 \\
\hline Linha/CC & $28,6 \mathrm{Ba}$ & $28,2 \mathrm{Bab}$ & $25,3 \mathrm{Ac}$ & $27,2 \mathrm{ABb}$ & $22,9 \mathrm{Ad}$ & $25,3 \mathrm{Bc}$ \\
\hline Entrelinha/CC & $28,3 \mathrm{Bab}$ & $28,4 \mathrm{Bab}$ & $25,2 \mathrm{Af}$ & $27,0 \mathrm{Bcd}$ & $22,7 \mathrm{Ag}$ & $24,8 \mathrm{Bf}$ \\
\hline Linha/SC & $29,9 \mathrm{Aa}$ & $29,2 \mathrm{ABb}$ & 25,8 Ae & $27,9 \mathrm{ABc}$ & $22,6 \mathrm{Af}$ & 26,6 Ade \\
\hline Entrelinha/SC & $30,4 \mathrm{Aa}$ & 29,8 Aab & $25,7 \mathrm{Ae}$ & $28,0 \mathrm{Ac}$ & $22,6 \mathrm{Af}$ & 27,0 Acd \\
\hline
\end{tabular}

Médias seguidas pela mesma letra, minúsculas nas linhas e maiúsculas nas colunas, não diferem entre si, pelo teste de Tukey, ao nível de 5\% de significância. Means followed by the same letter, lowercase letters in the lines and uppercase letters in columns do not differ by Tukey test at $5 \%$ significance level.

\section{Efeito das precipitações sobre a $\mathrm{FCO}_{2}$}

Embora variações na $\mathrm{FCO}_{2}$ tenham sido observadas nos quatro tratamentos, após as precipitações na área de estudo, quando comparadas às médias diárias da $\mathrm{FCO}_{2}$, observou-se que o tratamento Linha/CC foi mais sensível às variações no teor de água no solo, e depois de um aumento inicial, ocorria uma rápida queda nos valores médios diários da $\mathrm{FCO}_{2}$. 
$\mathrm{Na}$ Linha/CC, houve aumento de $40 \%$ na $\mathrm{FCO}_{2}$, quando comparado o valor médio do dia 101 $\left(8,77 \mu \mathrm{mol} \mathrm{m} \mathrm{m}^{-2} \mathrm{~s}^{-1}\right)$ ao do dia $102\left(12,23 \mu \mathrm{mol} \mathrm{m} \mathrm{m}^{-2} \mathrm{~s}^{-1}\right)$. Em adição, três dias depois, no dia 104, a $\mathrm{FCO}_{2}$ caiu drasticamente para $4,63 \mu \mathrm{mol} \mathrm{m} \mathrm{m}^{-2} \mathrm{~s}^{-1}$, um valor $90 \%$ inferior ao observado no dia 101 , e $164 \%$ inferior ao observado no dia 102. Estes eventos podem ter relação com uma precipitação de $54 \mathrm{~mm}$ ocorrida na área de estudo, no dia 102, no período da tarde. Elevações no conteúdo de água no solo, com a ocorrência de eventos pluviométricos, favorecem a expulsão de quantidades significativas de $\mathrm{CO}_{2}$ do interior do solo, devido à infiltração de água nos espaços porosos (LINN \& DORAN, 1984; LAL, 2009).

PANOSSO et al. (2009), em estudos conduzidos em área de cana queimada, no interior de São Paulo, também observaram um aumento significativo na $\mathrm{FCO}_{2}$ após uma precipitação de 21 mm. RETH et al. (2005), estudando um modelo que permite estimar o efluxo de $\mathrm{CO}_{2}$ em solo desprovido de vegetação, observaram que a temperatura e o teor de água do solo foram os fatores que exerceram maior influência sobre a emissão de $\mathrm{CO}_{2}$ do solo.

De acordo com vários estudos, as variações abruptas nas condições de temperatura e umidade do solo explicam a intensidade das emissões de $\mathrm{CO}_{2}$ em curtos períodos de tempo (LINN \& DORAN, 1984; ALMAGRO et al., 2009; ALMARAZ et al., 2009; USSIRI \& LAL, 2009; PANOSSO et al., 2009; TEIXEIRA et al., 2010; SILVA-OLAYA et al., 2013). Assim, as precipitações pluviométricas afetam significativamente o fluxo de $\mathrm{CO}_{2}$ do solo (MORELL et al., 2010). Isso ocorre com maior intensidade em solos em que as práticas agrícolas realizam a quebra de sua estrutura física, colaborando com a infiltração da água no interior do solo (SAINJU et al., 2008).

As médias diárias da umidade do solo, durante o período avaliado, também apresentaram variações com o advento das chuvas na área de estudo. As maiores médias da Us foram observadas no dia 104, com exceção do tratamento Entrelinha/SC. Conforme discutido anteriormente, no dia 102, ocorreu precipitação de $54 \mathrm{~mm}$, o que colaborou para a elevação no teor de água do solo (Figura 4c).

Conforme foram observadas variações na $\mathrm{FCO}_{2}$ e na Us, após eventos chuvosos, foi realizada a análise de correlação entre as variáveis. Feita a análise, foram constados índices de correlação linear, negativo e significativo $(\mathrm{r}=-0,56 ; p<0,05)$, entre as médias diárias da $\mathrm{FCO}_{2}$ e Us na Linha/CC, e também negativo e significativo $(\mathrm{r}=-0,66 ; p<0,05)$ na Linha/SC, indicando que a umidade do solo afetou a emissão de $\mathrm{CO}_{2}$ do solo na linha de plantio (Figura 5). Na Entrelinha/CC e Entrelinha/SC, o valor da correlação foi não significativo $(p>0,05)$.
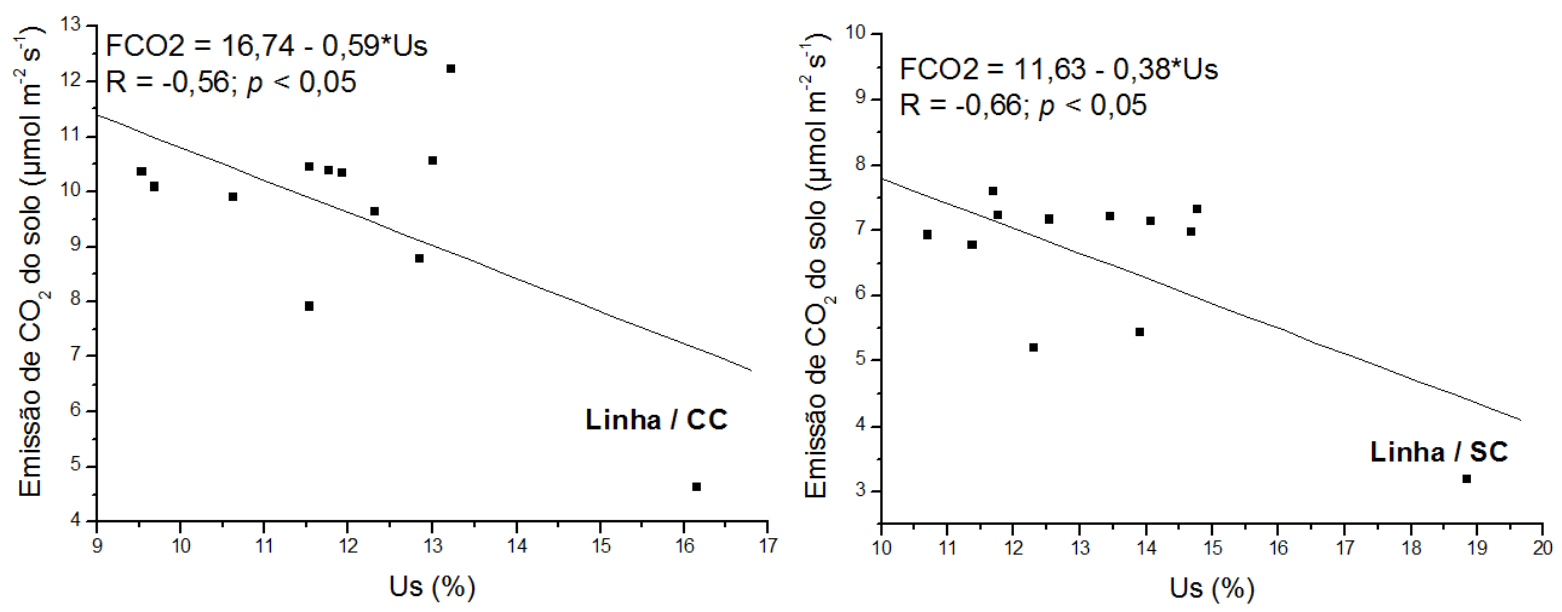

FIGURA 5. Correlação linear simples entre a emissão de $\mathrm{CO}_{2}$ e a umidade do solo nos tratamentos: Linha/CC e Linha/SC. Simple linear correlation between $\mathrm{CO}_{2}$ emission and soil moisture treatments: Row/CC and Row/SC. 
A exemplo do ocorrido neste estudo, de acordo com LAL (2009), o teor de água presente no solo pode tanto favorecer como inibir o processo de respiração do solo e a produção de $\mathrm{CO}_{2}$, uma vez que afeta a atividade microbiana e a difusão de gases. Esses efeitos são decorrentes, principalmente, da interação do conteúdo de umidade e do espaço poroso do solo (ORDÓÑEZFERNÁNDEZ et al., 2008). LINN \& DORAN (1984) observaram que a atividade microbiológica e as emissões de $\mathrm{CO}_{2}$ e $\mathrm{N}_{2} \mathrm{O}$ foram intensificadas em condições próximas a $60 \%$ de preenchimento dos poros por água. Entretanto, a atividade microbiana aeróbia diminuiu com valores acima de $60 \%$ como resultado da aeração reduzida.

Em adição, a análise de correlação linear simples entre a $\mathrm{FCO}_{2}$ e a Ts confirma a relação direta entre as variáveis (Figura 6). Houve correlação positiva e significativa na Linha/ $\mathrm{CC}(\mathrm{r}=0,76$; $p<0,001)$, assim como nos tratamentos: Linha/SC ( $\mathrm{r}=0,89 ; p<0,001)$ e Entrelinha/SC $(\mathrm{r}=0,66 ; p$ $<0,05)$. Esta relação pode ser claramente visualizada na Figura 4a e b, na qual as linhas da $\mathrm{FCO}_{2} \mathrm{e}$ Ts apresentam um padrão similar, variando de acordo com as precipitações pluviais (Figura 4a). De acordo com DAVIDSON et al. (2000), a respiração do solo aumenta proporcionalmente com a temperatura do solo, seguindo um modelo exponencial, uma vez que a temperatura do solo afeta diretamente a atividade microbiana e a respiração das raízes (SILVA-OLAYA et al., 2013), explicando por que maiores variações nas emissões são observadas em regiões de clima tropical.
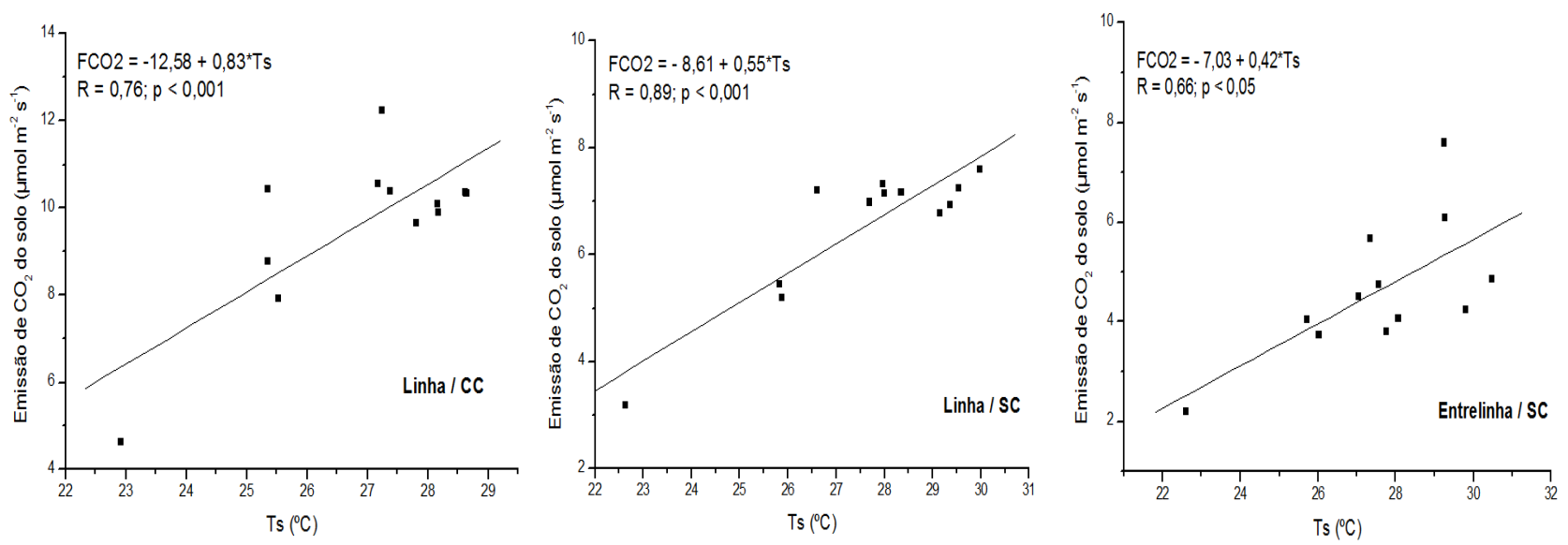

FIGURA 6. Correlação linear simples entre emissão de $\mathrm{CO}_{2}$ e a temperatura do solo nos tratamentos: Linha/CC, Linha/SC e Entrelinha/SC. Simple linear correlation between $\mathrm{CO}_{2}$ emission and soil temperature in managements: Row/CC, Row/SC and Interrow/SC.

\section{Emissão total de $\mathrm{CO}_{2}$ do solo no período de estudo}

Os valores obtidos da emissão total de $\mathrm{CO}_{2}$, contabilizados durante os 12 dias de estudo, nos diferentes tratamentos avaliados, também demonstram que o tratamento onde foi aplicado calcário na antiga linha da laranja (Linha/CC) foi responsável pela maior emissão total de $\mathrm{CO}_{2}$ do solo $\left(1.406,91 \mathrm{~kg} \mathrm{CO}_{2} \mathrm{ha}^{-1}\right)$, diferindo significativamente $(p<0,05)$ dos tratamentos: Linha/SC $(942,48$

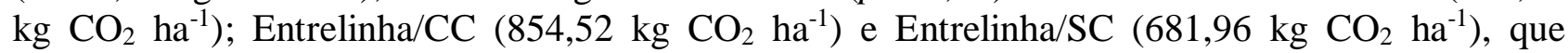
apresentaram o menor valor da emissão total de $\mathrm{CO}_{2}$ do solo durante o período de estudo (Figura 7).

O efeito da calagem sobre as emissões adicionais foi determinado pela subtração das emissões totais dos tratamentos onde o calcário foi aplicado (Linha/CC e Entrelinha/CC), dos tratamentos onde este não foi aplicado (Linha/SC e Entrelinha/SC). Quando comparados os tratamentos Linha/CC (1.406,90 kg CO ha $\left.^{-1}\right)$ e Linha/SC (942,48 $\mathrm{kg} \mathrm{CO}_{2}$ ha $\left.^{-1}\right)$, observa-se que emissões adicionais de 464,42 $\mathrm{kg} \mathrm{CO}_{2} \mathrm{ha}^{-1}$ foram induzidas pela aplicação do calcário no tratamento Linha/CC. Quando comparadas as emissões dos tratamentos Entrelinha/CC $\left(854,51 \mathrm{~kg} \mathrm{CO}_{2} \mathrm{ha}^{-1}\right)$ e Entrelinha/SC $\left(681,96 \mathrm{~kg} \mathrm{CO}_{2} \mathrm{ha}^{-1}\right)$, as emissões adicionais provocadas pelo calcário diminuíram para $172,55 \mathrm{~kg} \mathrm{CO}_{2} \mathrm{ha}^{-1}$, embora a mesma quantidade de calcário tenha sido aplicada tanto na linha quanto na entrelinha de plantio. 


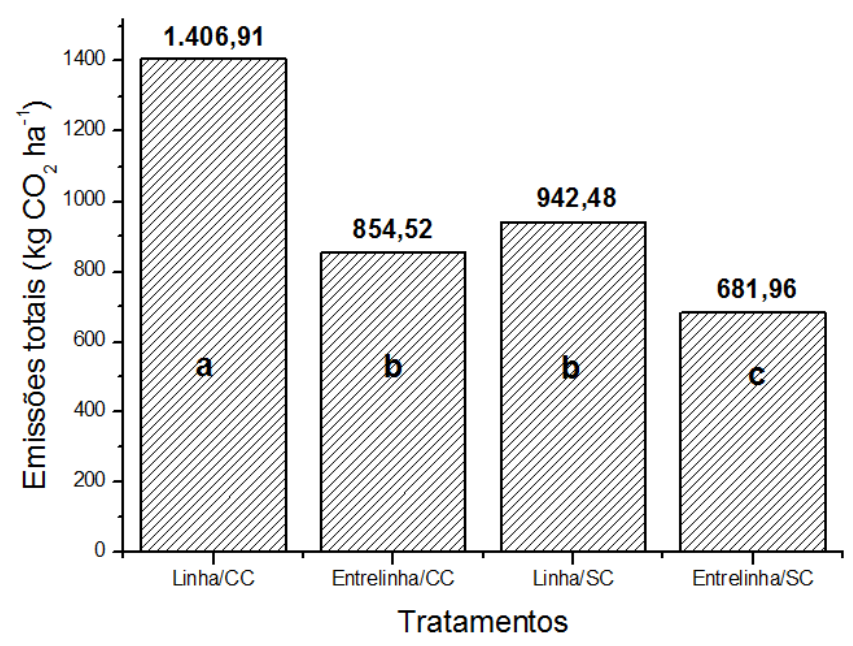

FIGURA 7. Emissão total de $\mathrm{CO}_{2}\left(\mathrm{~kg} \mathrm{ha}^{-1}\right)$ nos diferentes tratamentos avaliados em 12 dias de estudo. Valores médios com a mesma letra não diferem entre si, pelo teste de Tukey, ao nível de 5\% de probabilidade. Total emission of $\mathrm{CO}_{2}\left(\mathrm{~kg} \mathrm{ha}^{-1}\right)$ in the different evaluated treatments in $\mathbf{1 2}$ days of study. Mean values with the same letter do not differ by Tukey test at $5 \%$ probability.

Utilizando-se do fator de emissão de $\mathrm{CO}_{2}$ para aplicação de calcário dolomítico adotado pelo IPCC (2006), constatou-se a emissão adicional de $42 \%\left(0,464 \mathrm{t} \mathrm{CO}_{2} \mathrm{ha}^{-1}\right)$ em apenas 12 dias de estudo, de um total de 1,09 $\mathrm{t} \mathrm{CO}_{2} \mathrm{ha}^{-1}$ que, teoricamente, seriam emitidos dentro de um ano após a aplicação da calagem a uma taxa de 2,3 $\mathrm{t} \mathrm{ha}^{-1}$. DE FIGUEIREDO (2012), em estudo semelhante, observou valores correspondentes a 55,8\% e 52,8\% do conteúdo de carbono no calcário aplicado, supostamente liberado para a atmosfera na forma de $\mathrm{CO}_{2}$, em áreas de cana queimada (CQ) e cana crua sem resíduos sobre a superfície do solo (CCsemres), em 25 dias após a aplicação.

\section{CONCLUSÕES}

A emissão de $\mathrm{CO}_{2}$ do solo é influenciada tanto pela calagem quanto pela posição da aplicação (antigas linha e entrelinha da laranja). No entanto, a antiga linha da laranja apresenta as maiores emissões, independentemente da aplicação de calcário.

As precipitações favorecem as correlações lineares da $\mathrm{FCO}_{2}$ com a temperatura e a umidade do solo. A antiga linha da laranja apresenta maior sensibilidade às alterações da umidade do solo.

Estudos futuros são necessários para caracterizar e comparar a $\mathrm{FCO}_{2}$ nos ciclos adjacentes da cultura da cana-de-açúcar instalada sobre antigos pomares de laranja.

\section{REFERÊNCIAS}

ALMAGRO, M.; LÓPEZ, J.; QUEREJETA, J.I.; MARTÍNEZ-MENA, M. Temperature dependence of soil $\mathrm{CO}_{2}$ efflux is strongly modulated by seasonal patterns of moisture availability in a Mediterranean ecosystem. Soil Biology Biochemistry, Oxford, v.41, n.3 p.594-605, 2009.

ALMARAZ, J.J.; ZHOU, X.; MABOOD, F.; MADRAMOOTOO, C.; ROCHETTED, P.; MA, B. L.;SMITH, D.L. Greenhouse gas fluxes associated with soybean production under two tillage systems in Southwestern Quebec. Soil \& Tillage Research, Amsterdam, v.104, n.1, p.134-139, 2009.

BRITO, L.F.; MARQUES JÚNIOR, J.; PEREIRA, G.T.; SOUZA, Z.M.; LA SCALA, N. Soil CO2 emission of sugarcane field as affected by topography. Scientia Agricola, Piracicaba, v.66, n.1, p.77-83, 2009. 
CEPEA. Centro de Estudos Avançados em Economia Aplicada. A crise atual dos citricultores. Disponível em: < http://ruralcentro.uol.com.br/analises/cepea-analisa-a-crise-atual-dos-citricultores$3618 \# \mathrm{y}=480>$. Acesso em: 04 out. 2013.

CHAVEZ, L.F.; AMADO, T.J.C.; BAYER, C.; LA SCALA, N.; ESCOBAR, L.F.; FIORIN, J.E.; CAMPOS, B.C. Carbon dioxide efflux in a Rhodic Hapludox as affected by tillage systems in southern Brazil. Revista Brasileira de Ciência Solo, Viçosa, MG, v.33, n.2, p.325-334, 2009.

CONAB. Acompanhamento da safra brasileira: cana-de-açúcar, segundo levantamento, agosto/2012. Brasília. 2012 Disponível: < http://www.conab.gov.br/OlalaCMS/uploads/arquivos/12_09_05_09_11_59_boletim_cana_portugu es_-_agosto_2013_2o_lev.pdf Safra 2011/2012>. Acesso em: 06 set. 2013.

COSTA, F.S.; BAYER, C.; ZANATTA, J.A.; MIELNICZUK, J. Estoque de carbono orgânico no solo e emissões de dióxido de carbono influenciadas por sistemas de manejo no sul do Brasil. Revista Brasileira de Ciência Solo, Viçosa, MG, v.32, n.1, p. 323-332, 2008

DAVIDSON, E.A.; VERCHOT, L.V.; CATTÂNIO, H.; ACKERMAN, I.L.; CARVALHO, E.M. Effects of soil water content on soil respiration in forests and cattle pastures of eastern amazonia. Biogeochemistry, Dordrecht, v.48, n.1, p.53-69, 2000.

DE FIGUEIREDO. E.B. Balanço de gases de efeito estufa e emissões de $\mathrm{CO}_{2}$ do solo nos sistemas de colheita da cana-de-açúcar manual queimada e mecanizada crua. 2012. $111 \mathrm{f}$. Tese (Doutorado em Produção Vegetal) - Universidade Estadual Paulista, Faculdade de Ciências Agrárias e Veterinárias, Jaboticabal, 2012.

EMBRAPA - Empresa Brasileira de Pesquisa Agropecuária. Sistema brasileiro de classificação de solos. Rio de Janeiro. Ministério da Agricultura e do Abastecimento, 2006. 412p.

FUENTES, J.P.; BEZDICEK, D.F.; FLURY, M.; ALBRECHT, S.; SMITH, J.L. Microbial activity affected by lime in a long-term no-till soil. Soil Tillage \& Research, Amsterdam, v.88, n.1-2, p.123$131,2006$.

INTERGOVERNMENTAL PANEL ON CLIMATE CHANGE - IPCC. Climate Change 2007:

Mitigation. Contribution of Working Group III. Fourth Assessment Report of the Intergovernmental Panel on Climate Change. Cambridge: Cambridge University Press, 2007.

IPCC - Intergovernmental Panel on Climate Change: Guidelines for National Green House Gas Inventories. Prepared by the National Greenhouse Gas Inventories Programme. Japan: IGES, 2006. chapter 11.

KESSAVALOU, A.; DORAN, J. W.; MOSIER, A. R.; DRIJBER, R. A. Greenhouse gas fluxes following tillage and wetting in a wheatfallow cropping system. Journal of Environmental Quality, Madison, v.27, p.1105-1116, 1998.

LAL, R. Challenges and opportunities in soil organic matter research. European Journal of Soil Science, Malden, v.60, n.2, p.158-169, 2009.

LA SCALA, N.; LOPES, A.; SPOKAS, K.; BOLONHEZI, D.; ARCHER, D.W.; REICOSKY, D.C. Short-term temporal changes of soil carbon losses after tillage described by a first-order decay model. Soil \& Tillage Research, Amsterdam, v.99, n.1, p.108-118, 2008.

LA SCALA, N.; PANOSSO, A.R.; PEREIRA, G.T. Variabilidade espacial e temporal da emissão de $\mathrm{CO}_{2}$ num latossolo desprovido de vegetação. Engenharia Agrícola, Jaboticabal, v.23, n.1, p.8895, 2003.

LINN, D.M.; DORAN, J.W. Effect of water-filled pore space on carbon dioxide and nitrous oxide production in tilled and non-tilled soils. Soil Science Society of America Journal, Amsterdam, v.48, n.6, p. 1267-1272, 1984. 
MARCELO, A.V.; CORA, J.E.; LA SCALA, N. Influence of liming on residual soil respiration and chemical properties in a tropical no-tillage system. Revista Brasileira de Ciência do Solo, Viçosa, MG, v.36, n.1, p.45-50, 2012.

MORELL, F.J.; ÁLVARO-FUENTES, J.; LAMPURLANÉS, J.; CANTERO-MARTÍNEZ, C. Soil $\mathrm{CO} 2$ fluxes following tillage and rainfall events in a semiarid Mediterranean agroecosystem: effects of tillage systems and nitrogen fertilization. Agriculture, Ecosystems \& Environment, Amsterdam, v.139, n.1-2, p.167-173, 2010.

ORDÓÑEZ-FERNÁNDEZ, R.; CARBONELL BOJOLLO, R.; GONZÁLEZ-FERNÁNDEZ, P.; PEREA TORRES, F. Influencia de la climatología y el manejo del suelo en las emisiones de $\mathrm{CO}_{2}$ en un suelo arcilloso de la vega de Carmona. Carel, Amsterdam, v. 6, n.6, p. 2339-2354, 2008.

PANOSSO, A.R.; RIBEIRO, C.E.R.; ZANINI, J.R.; PAVANI, L.C.; PEREIRA, G.T.; LA SCALA, $\mathrm{N}$. Variabilidade espacial da emissão de $\mathrm{CO}_{2}$, da temperatura e umidade de um latossolo desprovido de vegetação sob diferentes lâminas de molhamento. Semina: Ciências Agrárias, Londrina, v.30, n.4, p.1017-1034, 2009.

R DEVELOPMENT CORE TEAM. R: A language and environment for statistical computing. Viena: R Foundation for Statistical Computing, 2011.

RETH, S.; MARKUS, R.; FALGE, E. The effect of soil water content, soil temperature, soil pHvalue and the root mass on soil $\mathrm{CO}_{2}$ efflux - A modified model. Plant and Soil, Dordrecht, v.268, n.1, p.21-33, 2005.

SAINJU, U.M.; JABRO, J.D.; STEVENS, W.B. Soil carbon dioxide emission and carbon content as affected by irrigation, tillage, cropping system, and nitrogen fertilization. Journal Environment Quality, Madison, v.37, n.1, p. 98-106, 2008.

SCHWARTZ, R.C.; BAUMHARDT, R.L.; EVETT, S.R. Tillage effects on soil water redistribution and bare soil evaporation throughout a season. Soil \& Tillage Research, Amsterdam, v.110, n.2, p.221-229, 2010.

SILVA-OLAYA, A.M.; CERRI, C.E.P.; LA SCALA JR., N.; DIAS, C.T.S.; CERRI, C.C. Carbon dioxide emissions under different soil tillage systems in mechanically harvested sugarcane.

Environmental Research Letters, Bristol, v.8, n.1, p.1-8, 2013.

SIX, J.; FREY, S. D.; THIES, R. K.; BATTEN, K. M. Bacterial and fungal contributions to carbon sequestration in agroecosystems. Soil Science Society America Journal, Madison, v.70, n.2, p.555$569,2006$.

TEIXEIRA, L.G.; LOPES, A; LA SCALA, N. Temporal variability of soil $\mathrm{CO}_{2}$ emission after conventional and reduced tillage described by an exponential decay in time model. Engenharia Agrícola, Jaboticabal, v.30, n.2, p.224-23, 2010.

USSIRI, D.A.N.; LAL, R. Long - term tillage effects on soil carbon storage and carbon dioxide emissions in continuous corn cropping system from an alfisol in Ohio. Soil \& Tillage Research, Amsterdam, v. 104, n.1, p.39-47, 2009.

WARRICK, A.W.; NIELSEN, D.R. Spatial variability of soil physical properties in the field. In: HILLEL, D. (Ed.) Applications of soil physics. New York: Academic Press, 1980. p. 319:344.

WANG, W.; FENG, J.; OIKAWA, T. Contribution of root and microbial respiration to soil $\mathrm{CO}_{2}$ efflux and their environmental controls in a humid temperate grassland of Japan. Pedosphere, Beijing, v.19, n.1, p.31-39, 2009. 